
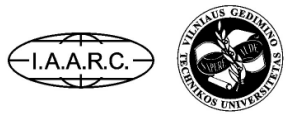

Institute of Internet and Intelligent Technologies

Vilnius Gediminas Technical University

Saulètekio al. 11, 10223 Vilnius, Lithuania

http://www.isarc2008.vgtu.lt/
The $25^{\text {th }}$ International Symposium on Automation and Robotics in Construction

June 26-29, 2008

ISARC-2008

\title{
SEISMIC RESPONSES OF CIVIL STRUCTURES UNDER MAGNETORHEOLOGICAL-DEVICE DIRECT CONTROL
}

\author{
M. T. Nguyen, H. Dalvand, Ying-Hao Yu, Q. P. Ha \\ Faculty of Engineering, University of Technology, Sydney \\ Broadway, NSW 2007, Australia \\ Email: \{minnguye, hedayatollah.dalvand, yinghao.yu, quangha\}@eng.uts.edu.au
}

\begin{abstract}
This paper presents an efficient control strategy for magnetorheological (MR) dampers embedded in building structures to mitigate quake-induced vibrations. In this work, MR dampers are used as semi-active devices, taking the advantages of the fail-safe operation and low power requirement. By using a static hysteresis model for the MR damper, a suitable controller is proposed here for direct control of the supply currents of the MR dampers using feedback linearization. The dampers are configured in a differential mode to counteract the force-offset problem from the use of a single damper. The effectiveness of the proposed technique is verified in simulation by using a ten-storey building model subject to quake-like excitations.
\end{abstract}

\section{KEYWORDS}

Structural control, MR dampers, semi-active control, seismic response

\section{INTRODUCTION}

There has been a great deal of research effort devoted to the area of building and civil infrastructure control. The ultimate objective for structural control is the suppression of earthquakeinduced vibrations or dynamic loadings as of wind or heavy loads [1]. Methodologies applied in building control are broadly classified into passive, active [2] and semi-active [3] categories. Active techniques require a certain amount of energy to drive the actuators to accomplish the control objective. On the other hand, a semi-active control system does not require much power to operate and its actuators can also be utilised in the passive mode. The philosophy adopted in these approaches is to effectively absorb the vibration energy by modifying the control device characteristics. The control devices may include fluid viscous, electrorheological (ER) and magneto-rheological (MR) dampers. In [4], a comparison was conducted on the efficiency and performance of approaches using semi-active against active tuned mass dampers for building control.

The MR dampers are promising devices in semiactive building control. In essence, they are equivalent in construction to conventional hydraulic dampers except that the dynamics of the fluids can be altered upon the application of currents induced magnetic fields. Compared with the ER damper, which is its analogy, the MR damper [5] requires a lower voltage which is very attractive for safety and practical reasons. In the building control paradigm, MR dampers can be applied in the passive mode [6] and in the brace configuration [7]. 
Commonly-used designs for MR damper control are based on Lyapunov stability, decentralised bangbang, maximum energy dissipation, modulated homogeneous and clipped-optimal control [8-10]. In the later approach, the value of the desired force is derived from a linear quadratic regulator (LQR) and a secondary current-control loop is used to obtain the appropriate current supplied to the dampers. All these controllers are affected via the damping force instead of controlling the current supplied to the MR damper.

Following the effort presented in [11], this work aims to develop a controller that can supply directly the magnetisation control current to the damper for building control with MR dampers integrated. Unlike [12], where the MR dampers were characterised by a well-known dynamic friction model, here we use current-input expressions describing explicitly the static hysteresis model for the damper force-velocity relationship [13] for the control design.

The remainder of the paper is organised as follows. In Section 2, the control system for building structure together with the damper configuration is modelled. The controller design is included in Section 3. Simulation results are given in Section 4 to verify the effectiveness of the proposed approach. Finally, a conclusion is drawn in Section 5.

\section{SYSTEM DESCRIPTION}

Consider a building model subject to vibration under the influence of the ground excitation $\ddot{x}_{g}$ during an earthquake. Let vibrational displacements of the storeys, $x_{p}(p=1, \ldots n$, where $n$ is the number of storeys) be assigned to each storey with respectively mass $m_{p}$, viscous damping coefficient $c_{p}$ and the stiffness coefficient $k_{p}$. These variables can be lumped into corresponding matrices $\mathbf{M}, \mathbf{C}$ and $\mathbf{K}$ to describe the motion of the building structure as

$\mathbf{M} \ddot{\mathbf{x}}+\mathbf{C} \dot{\mathbf{x}}+\mathbf{K x}=\Gamma f+\mathbf{M} \Lambda \ddot{x}_{g}$,

where $\ddot{\mathbf{x}}, \dot{\mathbf{x}}$ are the vectors respectively of storey accelerations and velocities, and $f$ is the overall force generated by the dampers installed on the first storey.
Matrix $\Gamma=\left[\begin{array}{llll}-1 & 0 & \ldots & 0\end{array}\right]^{T}$ is the gain matrix determining the control effect on the building, and $\boldsymbol{\Lambda}=\left[\begin{array}{lll}1 & \ldots & 1\end{array}\right]^{T}$ is a distribution matrix showing the effect of earthquake acceleration. By defining a system state $\mathbf{y}=\left[\begin{array}{ll}\mathbf{x}^{T} & \dot{\mathbf{x}}^{T}\end{array}\right]^{T}$ the motion equation can be further rewritten in the state-space form as

$\dot{\mathbf{y}}=\mathbf{A}_{0} \mathbf{y}+\mathbf{B}_{0} f+\mathbf{E}_{0}$,

$$
\begin{aligned}
& \mathbf{E}_{0}=\left[\begin{array}{c}
\mathbf{0} \\
\boldsymbol{\Lambda}
\end{array}\right] \ddot{x}_{g}, \mathbf{B}_{0}=\left[\begin{array}{c}
\mathbf{0} \\
\mathbf{M}^{-1} \boldsymbol{\Gamma}
\end{array}\right], \\
& \mathbf{A}_{0}=\left[\begin{array}{cc}
\mathbf{0} & \mathbf{I} \\
-\mathbf{M}^{-1} \mathbf{K} & -\mathbf{M}^{-1} \mathbf{C}
\end{array}\right],
\end{aligned}
$$

where $\mathbf{A}_{0}$ is the system matrix, $\mathbf{B}_{0}$ is the gain matrix, and $\mathbf{E}_{0}$ is the disturbance vector.

Here, counteract the force-offset problem for a single damper, a differential configuration of two identical dampers is used, as described in [13, 14]. Accordingly, the damper force generated by $j^{\text {th }} \mathrm{MR}$ damper is given by

$f_{i}=c_{d j} \dot{x}_{d j}+k_{d j} x_{d j}+\alpha_{d j} z_{d j}+g_{j}$,

where $z_{d j}=\tanh \left(\beta_{j} \dot{x}_{d j}+\delta_{j} \operatorname{sign}\left(x_{d j}\right)\right)$ and damper parameters $\quad c_{d j}, k_{d j}, \alpha_{d j}, g_{j}, \beta_{j} \quad$ depending explicitly on the supplied damper current [13] with: $c_{d 1}=c_{d 11}+c_{d 12} i_{d 1} ; k_{d 1}=k_{d 11}+k_{d 12} i_{d 1}$, as shown in Figure 1.

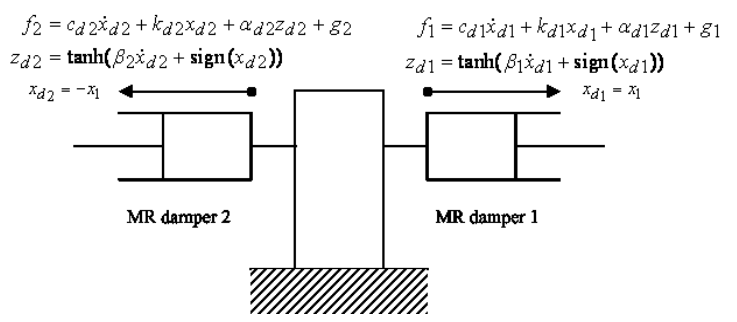

Figure 1. Damper differential configuration

Note that according to the proposed differential configuration, the damper displacements are opposite in sign, that is 
$x_{1}=x_{d 1}=-x_{d 2}, \dot{x}_{1}=\dot{x}_{d 1}=-\dot{x}_{d 2}$.

By assuming the two dampers are identical such that $i_{d 1}=i_{d 2}=i$, the effective damping force will be the difference of the damper forces, $f=f_{1}-f_{2}$, which will be used for vibration suppression and given by

$f=\bar{c}_{d 1} \dot{x}_{1}+\bar{k}_{d 1} x_{1}+\left(\bar{c}_{d 2} \dot{x}_{1}+\bar{k}_{d 2} x_{1}\right) i+\overline{\alpha z}_{d}$,

where $\bar{c}_{d j}=c_{d j 1}+c_{d j 2}, \quad \bar{k}_{d j}=k_{d j 1}+k_{d j 2}, \quad j=1,2$ and $\bar{\alpha}=\alpha_{d 1}+\alpha_{d 2}$.

\section{CONTROLLER DESIGN}

It is assumed that the differential damper configuration is installed on the first storey. The corresponding motion equation, e.g., for the first storey, can be rewritten as below to incorporate the damper current by noting (5):

$$
\begin{aligned}
m_{1} \ddot{x}_{1}+c_{1} \dot{x}_{1}+ & k_{1} x_{1}=m_{1} \ddot{x}_{g}-\left(\bar{c}_{d 1} \dot{x}_{1}+\bar{k}_{d 1} x_{1}\right) \\
& -\left(\bar{c}_{d 2} \dot{x}_{1}+\bar{k}_{d 2} x_{1}\right) i-\overline{\alpha z}_{d}
\end{aligned}
$$

where $m_{1}, c_{1}$ and $k_{1}$ represent respectively the mass, damping and stiffness of the first storey. Similar to (2), one can obtain

$\dot{\mathbf{y}}=\mathbf{A y}+\mathbf{B} i+\mathbf{E}$,

$$
\begin{aligned}
& \mathbf{A}=\left[\begin{array}{cc}
\mathbf{0} & \mathbf{I} \\
-\mathbf{M}^{-1} \overline{\mathbf{K}} & -\mathbf{M}^{-1} \overline{\mathbf{C}}
\end{array}\right], \\
& \mathbf{B}=\left[\begin{array}{c}
\mathbf{0}_{n} \\
-m^{-1}\left(\bar{c}_{d 2} \dot{x}_{1}+\bar{k}_{d 2} x_{1}\right) \\
\mathbf{0}_{n-1}
\end{array}\right], \mathbf{E}=\left[\begin{array}{c}
\mathbf{0}_{n} \\
-m_{1}^{-1} \bar{\alpha}_{d} \\
\mathbf{0}_{n-1}
\end{array}\right]+\left[\begin{array}{c}
\mathbf{0} \\
\mathbf{\Lambda}
\end{array}\right] \ddot{x}_{g},
\end{aligned}
$$

where $\mathbf{0}_{n}$ is a $n$-dimensional vector of zero entries, all elements of $\overline{\mathbf{K}}$ and $\overline{\mathbf{C}}$ remain the same as of $\mathbf{K}$ and $\mathbf{C}$ in (1), except $\bar{K}_{11}=K_{11}+\bar{k}_{d 1}$ and $\bar{C}_{11}=C_{11}+\bar{c}_{d 1}$.

Now, to make use of linear control techniques, consider a new control variable:

$$
u=\left(\bar{c}_{d 2} \dot{x}_{1}+\bar{k}_{d 2} x_{1}\right) i
$$

so that (7) becomes:

$$
\dot{\mathbf{y}}=\mathbf{A y}+\mathbf{B} u+\mathbf{E} \text {. }
$$

For example, an LQR controller can be designed to minimise the following cost function

$$
J=\int_{0}^{\infty}\left(\mathbf{y}^{T} \mathbf{Q y}+R u^{2}\right) d t,
$$

which yields

$$
u=-R^{-1} \mathbf{B}^{T} \mathbf{P y}=-\mathbf{K y},
$$

where $\mathbf{Q}$ is a given positive definite matrix and $R$ is a positive scalar and $\mathbf{P}$ is a positive definite matrix solving for a Riccati equation.

The control current is then obtained by

$$
i= \begin{cases}0, & i \leq 0 \\ u\left(\bar{c}_{d 2} \dot{x}+\bar{k}_{d 2} x\right)^{-1} & , 0 \leq i \leq i_{\max } \\ i_{\max }, & i_{\max } \leq i,\end{cases}
$$

wherein the value of $i_{\max }$ is determined by the maximal magnetisation in accordance with the physical properties of the MR fluid used in the damper.

\section{RESULTS}

\subsection{One-storey model}

To test the control performance, we use first a laboratorial set-up comprising a rectangular frame, emulating a single storey building, whose model parameters are given in [11].

A 0.5 -scaled record of the Northridge earthquake with a peak approximately at $1.7 \mathrm{~m} / \mathrm{s}^{2}$, enduring $30 \mathrm{~s}$ is used for excitation. For comparison purposes, the following criteria, adopted from [14], are used:

1. Absolute storey displacement ratio

$$
J_{1}=\frac{\max \left\{\left|x_{k, c}(t)\right|\right\}}{\max \left\{\left|x_{k, u}(t)\right|\right\}},
$$

where $k$ is the storey index and subscripts $c, u$ denote controlled and un-controlled displacement. 
2. Absolute storey acceleration ratio

$J_{2}=\frac{\max \left\{\left|\ddot{x}_{k, c}(t)\right|\right\}}{\max \left\{\left|\ddot{x}_{k, u}(t)\right|\right\}}$,

where the notation $\ddot{x}$ presents the storey acceleration.

3. Inter-storey drift ratio

$J_{3}=\frac{\max \left\{\left|\bar{x}_{k, c}(t)\right|\right\}}{\max \left\{\left|\bar{x}_{k, u}(t)\right|\right\}}$,

where the inter-storey displacement is given by $\bar{x}_{1}=x_{1}, \bar{x}_{k>1}=x_{k}-x_{k-1}$.

4. Root-mean-square storey displacement ratio

$J_{4}=\frac{\widetilde{x}_{k, c}(t)}{\widetilde{x}_{k, u}(t)}$,

where the RMS values are calculated from $\left.\tilde{x}=\sqrt{T^{-1} \sum\left\{\delta_{t} x_{k}^{2}(t)\right.}\right\}, \delta_{t}$ is the sampling time and $T$ is the total excitation duration.

5. RMS storey acceleration ratio

$J_{5}=\frac{\tilde{\ddot{x}}_{k, c}(t)}{\widetilde{\ddot{x}}_{k, u}(t)}$,

where the RMS values are calculated as above.

6. Average applied current

$J_{6}=\bar{i}=T^{-1} \sum\left\{\delta_{t} i(t)\right\}$,

which evaluates the economy of the proposed controller.

Figure 2 shows the responses (solid lines) of displacement, velocity and acceleration as compared to the no control responses (dotted lines) for the cases using the Lyapunov-based controller [11,14] (a) and this controller (b). Benchmarking with the criteria (12-18), the comparison between these two controllers are summarized in Table I. As can be seen from the simulation results and the evaluation table, the proposed controller demonstrates its effectiveness against the Lyapunov-based controller and also the reduction in quake-induced displacement is remarkable compared to that from no control.

Table 1. Evaluation: (a) Lyapunov-based controller $[11,14]$; (b) this proposed controller.

\begin{tabular}{|c|c|c|c|c|c|c|}
\hline Criteria & $J 1$ & $J 2$ & $J 3$ & $J 4$ & $J 5$ & $J 6$ \\
\hline (a) & 0.26 & 0.31 & 0.26 & 0.08 & 0.08 & 0.63 \\
\hline (b) & 0.09 & 0.14 & 0.09 & 0.03 & 0.03 & 0.40 \\
\hline
\end{tabular}

\subsection{Multi-storey model}

We next consider a ten-storey building model embedded with one pair of identical dampers to be placed on the first storey, with the parameters of the dampers given in [13]. Here, the building model has following structural parameters:

$$
\begin{aligned}
& m_{i}=98.3 \mathrm{~kg}, i=1 \ldots 10 ; \\
& c_{1}=75(\mathrm{Ns} / \mathrm{m}) ; c_{2 \ldots 10}=50(\mathrm{Ns} / \mathrm{m}) ; \\
& k_{1}=5.16 \times 10^{5}(\mathrm{~N} / \mathrm{m}) ; \\
& k_{2 \ldots 10}=6.84 \times 10^{5}(\mathrm{~N} / \mathrm{m}) .
\end{aligned}
$$

Figure 3(a) shows the seismic responses of the first storey for the cases using the proposed controller and without control (a), while the damping forces and the magnetizing current are shown respectively in Figure 3(b) and Figure 3(c). The evaluation results using criteria (12-17) are summarized in Table II for the case no control and with this controller (b). The results obtained verify the high performance of the proposed technique for direct control of smart structures using embedded MR dampers. 

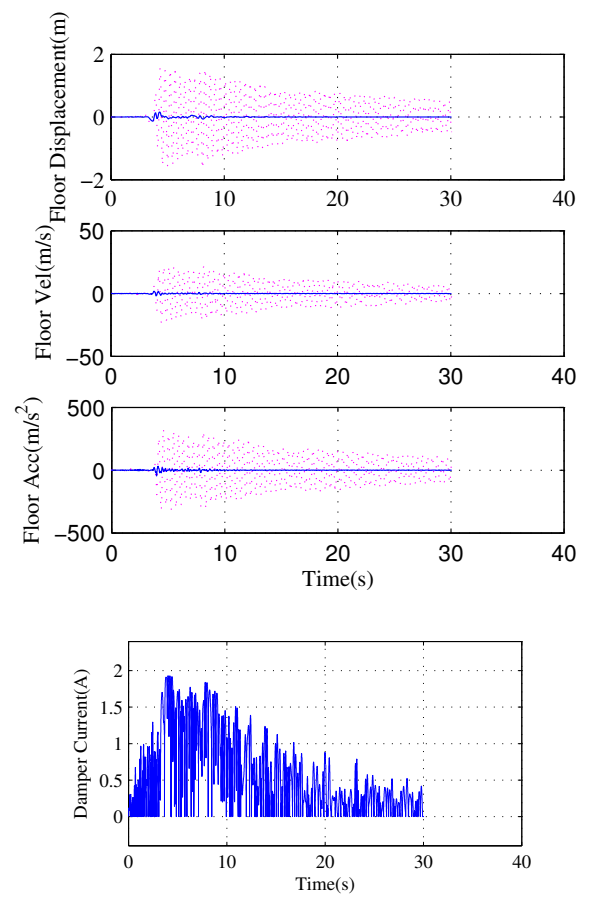

(a) Lyapunov-based direct control
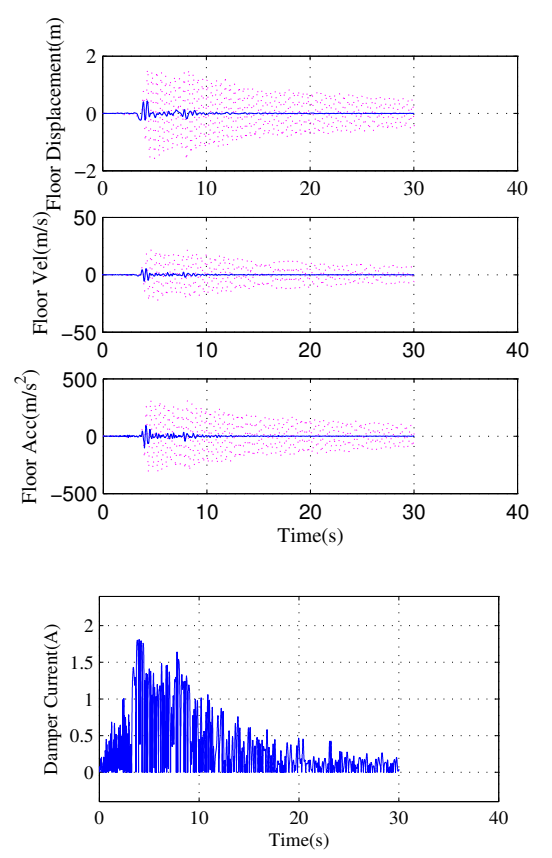

(b) This controller

Figure 2. One-storey quake-induced responses
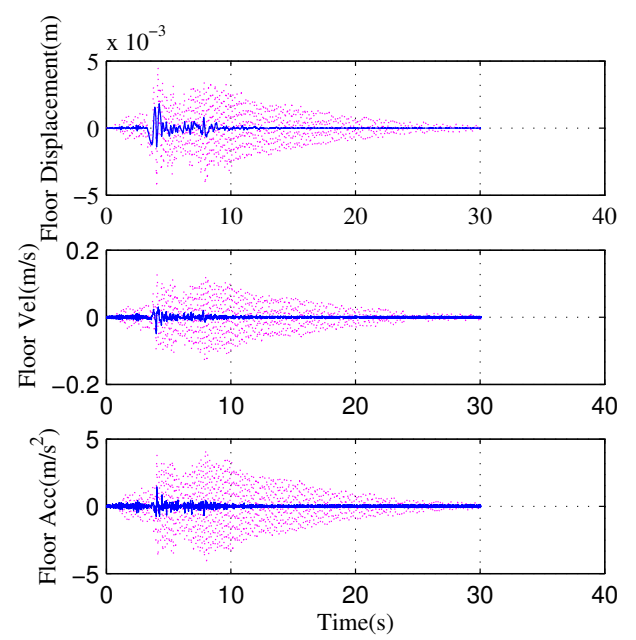

(a)

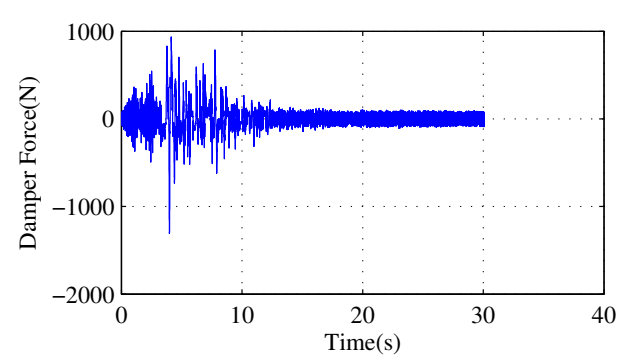

(b)

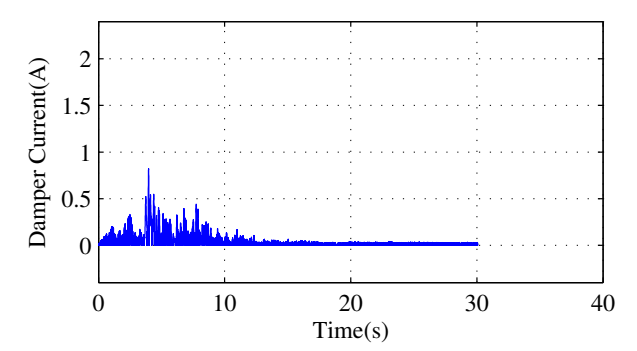

(c)

Figure 3. Multi-storey seismic responses: (a) $1^{\text {st }}$ storey displacements, velocity and accelerations (dotted - no control, solid - under control), (b) damper force, (c) current. 
Table 2. Evaluation (a) current $i=0$ :

\begin{tabular}{|c|c|c|c|c|c|}
\hline $\begin{array}{c}\text { Floors } / \\
\text { Criteria }\end{array}$ & $J_{1}$ & $J_{2}$ & $J_{3}$ & $J_{4}$ & $J_{5}$ \\
\hline $1^{\text {st }}$ & 0.75 & 0.55 & 0.75 & 0.53 & 0.38 \\
\hline $2^{\text {nd }}$ & 0.76 & 0.58 & 0.78 & 0.54 & 0.40 \\
\hline $3^{\text {rd }}$ & 0.77 & 0.63 & 0.79 & 0.55 & 0.43 \\
\hline $4^{\text {th }}$ & 0.78 & 0.67 & 0.81 & 0.55 & 0.47 \\
\hline $5^{\text {th }}$ & 0.79 & 0.69 & 0.76 & 0.56 & 0.51 \\
\hline $6^{\text {th }}$ & 0.82 & 0.72 & 0.72 & 0.56 & 0.55 \\
\hline $7^{\text {th }}$ & 0.81 & 0.76 & 0.68 & 0.56 & 0.56 \\
\hline $8^{\text {th }}$ & 0.75 & 0.55 & 0.75 & 0.53 & 0.38 \\
\hline $9^{\text {th }}$ & 0.76 & 0.58 & 0.78 & 0.54 & 0.40 \\
\hline $10^{\text {th }}$ & 0.77 & 0.63 & 0.79 & 0.55 & 0.43 \\
\hline
\end{tabular}

(b) this proposed controller:

\begin{tabular}{|c|c|c|c|c|c|}
\hline $\begin{array}{c}\text { Floors / } \\
\text { Criteria }\end{array}$ & $J_{1}$ & $J_{2}$ & $J_{3}$ & $J_{4}$ & $J_{5}$ \\
\hline $1^{\text {st }}$ & 0.65 & 0.56 & 0.65 & 0.45 & 0.32 \\
\hline $2^{\text {nd }}$ & 0.69 & 0.48 & 0.75 & 0.47 & 0.34 \\
\hline $3^{\text {rd }}$ & 0.70 & 0.54 & 0.74 & 0.48 & 0.37 \\
\hline $4^{\text {th }}$ & 0.71 & 0.59 & 0.74 & 0.48 & 0.41 \\
\hline $5^{\text {th }}$ & 0.73 & 0.60 & 0.69 & 0.49 & 0.45 \\
\hline $6^{\text {th }}$ & 0.75 & 0.63 & 0.63 & 0.49 & 0.48 \\
\hline $7^{\text {th }}$ & 0.73 & 0.68 & 0.58 & 0.49 & 0.49 \\
\hline $8^{\text {th }}$ & 0.71 & 0.66 & 0.59 & 0.49 & 0.48 \\
\hline $9^{\text {th }}$ & 0.70 & 0.59 & 0.60 & 0.49 & 0.47 \\
\hline $10^{\text {th }}$ & 0.70 & 0.59 & 0.64 & 0.49 & 0.46 \\
\hline
\end{tabular}

\section{CONCLUSION}

This paper has presented an effective semi-active control approach for building structures embedded with MR dampers for mitigation of the vibrations induced from seismic excitations. The control system is based on a differential configuration of the dampers to avoid damper offset forces, and linearized control strategy to directly issue the magnetising currents to the MR dampers in the presence of seismic excitations. Comparisons between the passive mode $(i=0)$ and semi-active mode with different controllers are made to show the efficiency and effectiveness of the proposed scheme.

\section{ACKNOWLEDGEMENT}

This work is funded by Australian Research Council (ARC) project DP0559405 and, in part, by the Centre of Excellence program, funded by the ARC and the New South Wales State Government.

\section{REFERENCES}

[1] Nishitani, A. \& Inoue Y. (2001) Overview of the application of active/semiactive control to building structures in Japan, Earthquake Engineering and Structural Dynamics, Vol. 30, No. 11, 1565-1574.

[2] Datta, T.K. (2003) A state-of-the-Art Review on Active Control of Structures, ISET Journal of Earthquake Technology, Vol. 41, No. 1, 1-17.

[3] Symans, M.D. \& Constaninou, M.C. (1999) Semiactive Control Systems for seismic Protection of Structures: A State-of-the-Art Review, Engineering Structures, Vol. 21, 469-487.

[4] Lin, P.Y., Chung, L.L. \& Loh, C.H. (2005) Semiactive Control of Building Structures with Semiactive Tuned Mass Dampers, Computer-Aided Civil and Infrastructure Engineering, Vol. 20, 3551.

[5] Carlson, D., Catanzarite, D.M. \& Clair, K.A.S. (1996) Commercial Magnetorheological Fluid Devices, International Journal of Modern Physics $B$, Vol. 10, 2857-2865.

[6] Cho, S.W., Jung, H.J. \& Lee, I.W. (2005) Smart Passive System Based on Magnetorheological Damper, Smart Materials and Structures, Vol. 14, 707-714.

[7] Hiemenz, G.J., Choi, Y.T. \& Wereley, N.M. (2003) Seismic Control of Civil Structures Ultilizing Semiactive MR Braces, Computer-Aided Civil and Infracture Engineering, Vol. 18, 31-44.

[8] Dyke, S. J., Spencer, Jr. B. F., Sain, M. K. \& Carlson, J. D. (1996) Modeling and control of magnetorheological dampers for seismic response reduction, Smart Materials and Structures, Vol. 5, 565-575.

[9] Yoshida, O. \& Dyke, S.J. (2004) Seismic Control of a Nonlinear Benchmark Building Using Smart Dampers, Journal of Engineering Machanics, Vol. 130, No. 4, 386-392.

[10] Djajakesukma, S.L., Samali, B. \& Nguyen H., (2002) Study of a Semi-active Stiffness Damper under Various Earthquake Inputs, Earthquake Engineering and Structural Dynamics, Vol. 31, 1757-1776.

[11] Nguyen, M.T., Kwok, N.M., Ha, Q.P., Li, J. \& Samali, B. (2007), "Semi-active direct control of civil structure seismic responses using magnetorheological dampers," Proc. 24th Int. Sym. 
Automation and Robotics in Construction, Chennai India, September 2007, pp. 157-162.

[12] Alvarez, L. \& Jimenez, R. (2003) Semi-active Control of Civil Structures Using Magnetorheological Dampers, Proceedings of American Control Conference, Denver, Colorado, 1428-1433.

[13] Kwok, N.M., Ha, Q.P., Nguyen, T.H., Li, J. \& Samali, B. (2006) A Novel Hysteretic Model for
Magnetorheological Fluid Dampers and Parameter Identification Using Particle Swarm Optimization, Sensors \& Actuators A: Physical, Vol. 132, No. 2, 441-451.

[14] Ha, Q.P., Kwok, N.M., Nguyen, M.T., Li, J. \& Samali, B. (2008) "Mitigation of Seismic Responses of Building Structures using MR Dampers with Lyapunov-Based Control," Structural Control and Health Monitoring, online June 2007. 